\title{
Preparation of Water Based Polymeric Binders for Paper Surface Coating
}

\author{
Samya El-Sherbiny ${ }^{*}$, Fatma A. Morsy', Ayman M. Atta², Salwa A. Ahmed ${ }^{1}$ \\ ${ }^{1}$ Chemistry Department, Faculty of Science, Helwan University, Helwan, Egypt \\ ${ }^{2}$ Surfactants Research Chair, Chemistry Department, College of Science, King Saud University, Riyadh, KSA \\ Email: *samya.elsherbiny@gmail.com
}

Received 30 January 2014; revised 28 February 2014; accepted 27 March 2014

Copyright (C) 2014 by authors and Scientific Research Publishing Inc.

This work is licensed under the Creative Commons Attribution International License (CC BY).

http://creativecommons.org/licenses/by/4.0/

(c) (i) Open Access

\begin{abstract}
Binder is an important ingredient in pigment coating as it is used to impart adhesion, gloss and flexibility to the dried film as well as binding the pigment particles together. The aim of this work was to synthesize polymeric binders via radical copolymerization of acrylic acid (AA) with maleic anhydride (MA) and with 2-acrylamido-2-methyl-1-propane sulfonic acid (AMPS). The chemical structures of the prepared binders were characterized by FTIR and ${ }^{1}$ HNMR analysis. The rheology of the prepared binders was also investigated. The prepared binders were applied in paper coating suspensions and their effects on optical, mechanical, and physical properties in addition to printability of the coated paper were studied. The results showed that acrylic maleic anhydride copolymers increased the adhesion, gave good film forming properties and good surface activity which increased print quality of paper coating. It was also found that MA/AA (50:50) and the blend between MA/AA (50:50) with AMPS:AA (30:70) have more suitable coating film properties and have highest pick resistance which is resemble to the commercial binder.
\end{abstract}

\section{Keywords}

Maleic Anhydride, Acrylic Acid, Paper Coating, Binder, Adhesion, Print Quality

\section{Introduction}

Pigment coatings are applied to paper to improve the appearance, printing qualities and other properties of paper [1]. Pigment coating covers the fibers of paper surface and fills in the interstices on the surface and renders the paper more level and uniform in texture. The coat layer reduces the penetration of ink into the paper sheet. Therefore, the ink does not spread as much and the print image is clear and sharp. The print density and the print

${ }^{*}$ Corresponding author.

How to cite this paper: El-Sherbiny, S., et al. (2014) Preparation of Water Based Polymeric Binders for Paper Surface Coating. Journal of Surface Engineered Materials and Advanced Technology, 4, 140-154.

http://dx.doi.org/10.4236/isemat.2014.43018 
gloss are enhanced, and the ink demand is reduced compared to uncoated papers [2]-[4].

Coating mixture consists primarily of pigments dispersed in water, plus binders, cobinders and other additives [5]-[7]. The pigment content of the coating composition provides the desirable qualities of the coating [8] [9]. Binder is added to bind pigment particles to paper, bind pigment to each other and to fill voids between pigment particles so that the coating layer will not be removed by pull of printing ink during the printing operation [10]. Binders are desired to meet various requirements such as good binding power, mixed and dissolved easily in water, good chemical and mechanical properties and harmless to health [11]. There is no synthetic binder which could meet all requirements of good binder so it is often need co-binder to adjust the rheology and water retention to the required level [12]. Acrylic binders have found significant uses in the field of paper coating for clear grease-resistant coating, excellent mixture quality, resistance to oil and solvent and permanent flexibility. Additionally, acrylate dispersions have an excellent brightness and ageing resistance and are less odorous [13]. Copolymers of maleic compounds with ethylenically unsaturated monomers such as the copolymer of styrene, vinyl esters, vinyl ethers, vinyl halides, acrylonitrile acrylic acid, methacrylic acid and esters with maleic anhydride have been known for some time. The majority of these copolymers are based on maleic anhydride and the polymerization is carried out in organic solvent systems and in few times in aqueous media. It has many interesting characteristics such as high thermal stability, tuneable solubility, and good film forming properties [14] [15]. Acrylic polymer makes co-polymer with maleic anhydride which shows a small tendency for radical homo-polymerization [16], but readily reacts with olefins, dienes, ethers and aromatic compounds to give alternating copolymers [17] [18].

This work aims to prepare paper coating binders based on copolymerization between different ratio of a water soluble maleic anhydride with acrylic acid (MA/AA) and copolymerization of acrylic acid with 2-Acrylamido2-Methylpropane Sulfonic Acid (AMPS/AA).

The effect of these various types of binder on coated paper properties as optical, mechanical and physical properties were studied and then were compared with commercial binder Acronal S 360D.

\section{Experimental}

\subsection{Materials}

The Acrylic acid, maleic anhydride, benzoyl peroxide, and 2-acrylamido-2-methylpropane sulfonic acid (AMPS) were obtained from Aldrich Chemical Co., (Germany).

Commercial binder (Acronal S 360D, BASF), china clay pigment (Rakta company) and sodium hexametaphosphate dispersant (99\%, fine chemical company) were used for preparation of coating mixture.

\subsection{Copolymers Preparation}

\subsubsection{Preparation of Acrylic Acid/Maleic Anhydride Copolymer (MA/AA)}

A four-neck $500 \mathrm{ml}$ round bottom flask, equipped with reflux condenser, thermometer, nitrogen inlet, mechanical stirrer and constant-addition syringe drive pump, was charged with $255 \mathrm{~g}$ acetone, 1 mol of maleic anhydride (50 mol\%) and $0.85 \mathrm{~g}$ benzoyl peroxide. The flask was purged with dry nitrogen while the resulting solution was heated under agitation to reflux (about $90^{\circ} \mathrm{C}$ ), the system being maintained thereafter under a static nitrogen pressure. The continuous addition of $1 \mathrm{~mol}(50 \mathrm{~mol} \%)$ of acrylic acid to the solution was started once the solution temperature reached $90^{\circ} \mathrm{C}$. The acid addition continuing is over a period of 3 hours. The polymerization solution was refluxed for 3 hours following completion of the acrylic acid addition. Then the resulting mixture was distilled atmospherically to remove the acetone solvent to produce an aqueous solution of hydrolyzed copolymer. The polymerization process was pronounced at different ratios of maleic anhydride: acrylic acid (90:10, 70:30, 50:50, 30:70, and 10:90) and another trial at (2:1 mole; and 1:2 mole) to obtain a homogeneous hydrolyzed acrylate maleate copolymers with various maleic acrylic ratios.

\subsubsection{Preparation of Acrylic Acid-2-Acrylamido-2-Methylpropane Sulfonic Acid Copolymer (AMPS/AA)}

A 3-neck $500 \mathrm{ml}$ round bottom flask, equipped with reflux condenser, thermometer, nitrogen inlet, mechanical stirrer, was charged with 1 mole (50\%) AMPS, 1 mole (50\%) acrylic acid and 25\% distilled water. The flask was purged with dry nitrogen while the resulting solution was heated under agitation to reflux (about $60^{\circ} \mathrm{C}$ ) the 
system being maintained thereafter under a static nitrogen pressure. The continuous addition of initiator $(0.1 \%)$ potassium peroxide dissolved in $10 \mathrm{ml}$ distilled water to the solution was started once the solution temperature reached $60^{\circ} \mathrm{C}$, the initiator addition continuing over a period of 2 hours. The polymerization solution was refluxed for 2 hours following completion of the initiator addition to produce a colorless or light yellow liquid copolymer, the polymerization process was pronounced at different ratios of AMPS: acrylic acid: (20:80, 30:70, 50:50, 60:40, and 90:10).

\subsection{Copolymers Characterization}

The prepared polymers were investigated by various analysis tools such as ${ }^{1} \mathrm{H}-\mathrm{NMR}$. The spectra of the prepared polymers were recorded on a $500 \mathrm{MHz}$ using JEOL-ECA-500, Japan spectrometer while, infrared were determined with FTIR (KBR) JASCO, Japan, model 6100, also the rheological properties of the polymers were studied by using ERV-8 viscometer, UK Ltd.

\subsection{Preparation of Paper Coating Suspensions}

The basic coating formula used in this study, was a typical standard coating mixture consisted of $100 \mathrm{pph}$ (pph = part per 100 parts of dry pigment) china clay pigment and $10 \mathrm{pph}$ binder.

The clay was dispersed in distilled water in the presence of $0.3 \mathrm{pph}$ sodium hexametaphosphate at a solids content of $50 \%$ and a pH of 8.5 . The solids content was adjusted to $40 \%$ after addition of binder then the pH was adjusted to 8 using a $1 \mathrm{M} \mathrm{NaOH}$ solution.

The copolymers which were successfully applied to coating suspension are shown in Table 1.

\subsection{Preparation of Coated Paper Samples}

A K-bar semiautomatic coater was used for applying the coating mixtures. A wire-wound coating bar was chosen to give a $6 \mu \mathrm{m}$ thick wet film. Paper samples to be coated were cut to overall dimensions of $200 \times 300 \mathrm{~mm}^{2}$. All paper sheets were supercalendered at $80^{\circ} \mathrm{C}$ and a pressure of 90 bars for 20 minutes.

\subsection{Coated Paper Characterization}

The properties of coated papers were evaluated using standard testing for physical, optical and mechanical properties. The paper surface roughness (Bendtsen Tester, model K531, Messmer Bunchel) was measured in accordance with ISO 8791-2. The optical properties (i.e. brightness) were measured using (Brightness and Colourmeter instrument, model 68-59-00-002, Buchel-B.V, Netherlands) in accordance with ISO 2470-1 (2009) and the paper gloss was measured by Micro Glossmeter, measurement at angle $75^{\circ}$. Where The tensile strength and burst strength were determined using T-series; model H5KT, Tinius Olsen Ltd, at $1 \mathrm{KN}$ according to ISO 1924-2 standard and burst tester; model BT-10 TIS Techlab Systems, according to ISO 2758-3(2009), respectively.

Table 1. The commercial and prepared binders used in preparation of coated paper.

\begin{tabular}{cc} 
Binder & Mol ratio \\
Commercial binder & Acronal S 360R \\
Maleic anhydride : Acrylic acid & $90: 10$ \\
Maleic anhydride : Acrylic acid & $50: 30$ \\
Maleic anhydride : Acrylic acid & $50: 50$ \\
Maleic anhydride : Acrylic acid & $30: 70$ \\
Maleic anhydride : Acrylic acid & $10: 90$ \\
Maleic anhydride : Acrylic acid & $2: 1$ \\
Maleic anhydride : Acrylic acid & $1: 2$ \\
Blend (MA/AA 50:50 : AMPS/AA 30:70) & $50: 50$ \\
\hline
\end{tabular}




\subsection{Printing Process}

For offset printing, the IGT printability tester, model AIC 2-5 series w, Reprotest B.V, Amsterdam, Holland reporting ISO 2834-1(2006) was used. Paper specimens of various coated papers were prepared in strips of $6 \times 30$ $\mathrm{cm}$ by using a laboratory paper cutter. An offset ink supplied by Paints and Chemical Industries Company (Packin) was used.

\section{Results and Discussion}

\subsection{Binder Characterizations}

\subsubsection{Copolymerization of MA/AA}

In the present study, the high conversion copolymerization of MA and AA was carried out using solution radical copolymerization as represented in the experimental section. The structure of MA/AA copolymers is confirmed by IR and ${ }^{1} \mathrm{H}$ NMR spectroscopy. IR spectra of MA/AA copolymers having different compositions were represented in (Figure 1). ${ }^{1}$ HNMR spectra of MA/AA copolymers were illustrated in (Figure 2). IR spectra of MA/AA copolymers show strong absorption peak at $3500-2800 \mathrm{~cm}^{-1}$ indicates the presence of carboxylic acid groups which confirms the presence of AA in the produced copolymers. The presence of two absorption peaks at 1810 and $1770 \mathrm{~cm}^{-1}$, assigned for the carbonyl of the anhydride group, confirms the presence of MA in the structure of the produced copolymers. The appearance of these bands indicates that the anhydride groups were not hydrolyzed during the copolymerization of AA with MA [19]. It was also observed that, the absorption bands at 3100 and $1600 \mathrm{~cm}^{-1}$, assigned to $=\mathrm{CH}$ and $\mathrm{C}=\mathrm{C}$, disappeared in all spectra of MA/AA copolymers and confirm the complete polymerization of AA and MA monomers. ${ }^{1} \mathrm{HNMR}$ analysis is used to confirm the copolymerization of AA and MA as illustrated in Figure 2. This was estimated through the disappearance of $\mathrm{HC}=\mathrm{CH}$

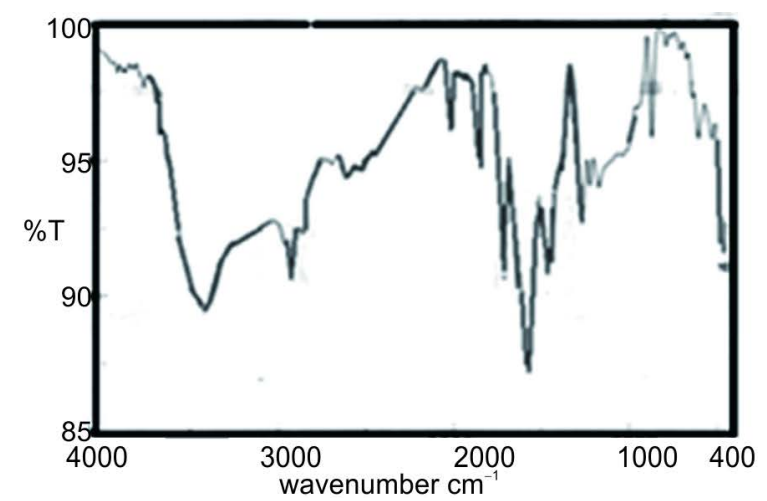

(a)

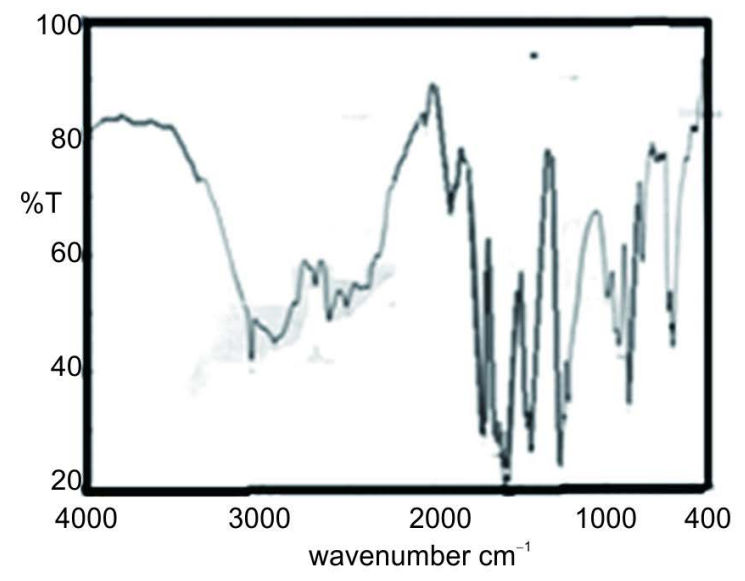

(c)

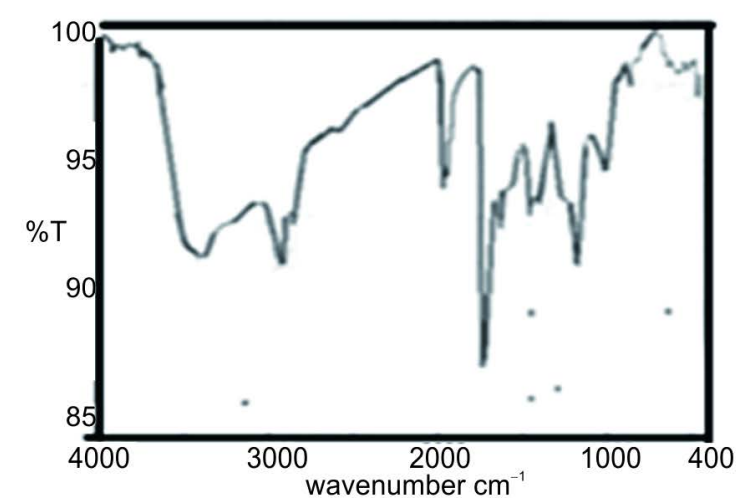

(b)

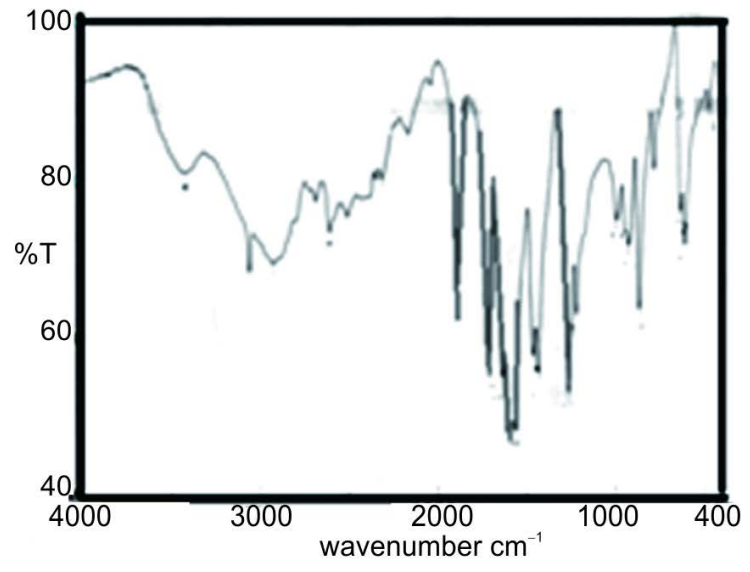

(d)

Figure 1. FTIR spectra of linear MA/AA copolymers (a) 10/90, (b) 30/70, (c) 50/50 and (d) 90/10. 


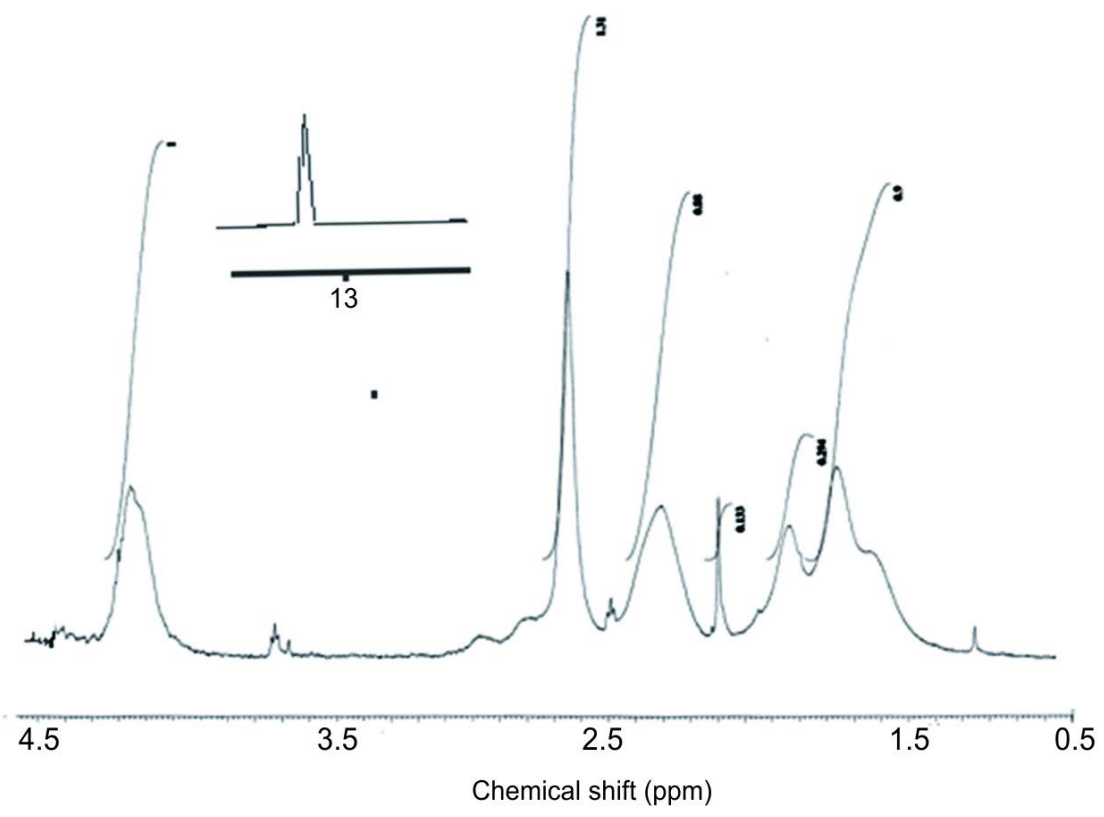

Figure 2. ${ }^{1} \mathrm{HNMR}$ analysis of MA/AA copolymers.

and $\mathrm{H}_{2} \mathrm{C}=\mathrm{CH}$ peaks at 6.7 and $4.5 \mathrm{ppm}$ of MA and AA, respectively [20]. The appearance of the carboxyl proton $-\mathrm{COOH}$ at $13.3 \mathrm{ppm}$ indicated the copolymerization of AA monomer. The peaks at $1.5-2.6 \mathrm{ppm}$ and $4.2 \mathrm{ppm}$ were assigned to backbone methylene and $\mathrm{CH}$ protons $\mathrm{MA}$ and $\mathrm{AA}$, respectively.

\subsubsection{Copolymerization of AMPS/AA}

The chemical structure of AMPS/AA was evaluated by IR and ${ }^{1} \mathrm{H}$ NMR analyses. The IR spectra of AMPS/AA were represented in (Figure 3). The ${ }^{1}$ HNMR spectra of AMPS/AA copolymer were illustrated in (Figure 4). The appearance of the absorption pattern of AMPS/AA between 3500 and $2800 \mathrm{~cm}^{-1}$ indicates the presence of extensive inter and intra-hydrogen bonds between hydroxyl groups and hydrogen protons of both the $\mathrm{COOH}$ and $\mathrm{SO}_{3} \mathrm{H}$ of AMPS/AA copolymers. The disappearance of strong absorption bands at 3100 and $1640 \mathrm{~cm}^{-1}$ which noted in all spectra indicated the polymerization of AMPS and AA monomers. These peaks are referred to stretching of C-H vinyl and $\mathrm{C}=\mathrm{C}$ bonds of vinyl groups of both AMPS and AA. The bands of the stretching of $\mathrm{S}-\mathrm{O}$ at $910 \mathrm{~cm}^{-1}$ and the symmetric $\mathrm{S}=\mathrm{O}$ stretching at $1043 \mathrm{~cm}^{-1}$, are observed and indicate the presence of $\mathrm{SO}_{3} \mathrm{H}$ of AMPS in the structure of AMPS/AA copolymers. Furthermore, the band at $1400 \mathrm{~cm}^{-1}$ (asymmetric $\mathrm{S}=\mathrm{O}$ stretching) indicates the presence of $\mathrm{SO}_{3} \mathrm{H}$. The copolymerization of AMPS with AA was elucidated by ${ }^{1} \mathrm{H}$ NMR analysis (Figure 4). The appearances of new signals at $13.3 \mathrm{ppm}$ and $8.6 \mathrm{ppm}$, which represent both $\mathrm{COOH}$ and $\mathrm{SO}_{3} \mathrm{H}$, respectively, indicate the incorporation of both AMPS and AA in the produced polymers. The signals at 1.5 - $2.6 \mathrm{ppm}$ and $4.2 \mathrm{ppm}$ were assigned to backbone methylene and $\mathrm{CH}$ protons $\left(\mathrm{COOH}\right.$ and $\left.\mathrm{SO}_{3} \mathrm{H}\right)$, respectively. The disappearance of signals from 4.5 to $5.5 \mathrm{ppm}$, represented $\mathrm{H}_{2} \mathrm{C}=\mathrm{CH}$ vinyl groups of both AA and AMPS indicated also the polymerization of both AMPS and AA monomers.

\subsection{Rheology Measurements}

The rheology of various types of the prepared binders represented in Figure 5 and Figure 6, show a decrease in viscosity as the shear rate was increased. Accordingly, it was found that all the prepared binders are thinning polymers (a thixotropic material) which become more fluid with increasing time of applied force or increasing the shear rate. A regular decrease in commercial polymer (Acronal) viscosity as the shear rate increased, was found where MA:AA (50:50), MA:AA (1:2) and AMPS/AA (30:70) binders respectively, have the least thinning effect comparing with this type commercial binder. This means that a high network structure is created within the polymer molecules. Figure 5 also shows that MA:AA (90:10), MA:AA (70:30), MA:AA (30:70), MA:AA (10:90), and MA:AA (2:1) polymers respectively, have a high decrease in viscosity as the shear rate increased compared with MA:AA (50:50). 


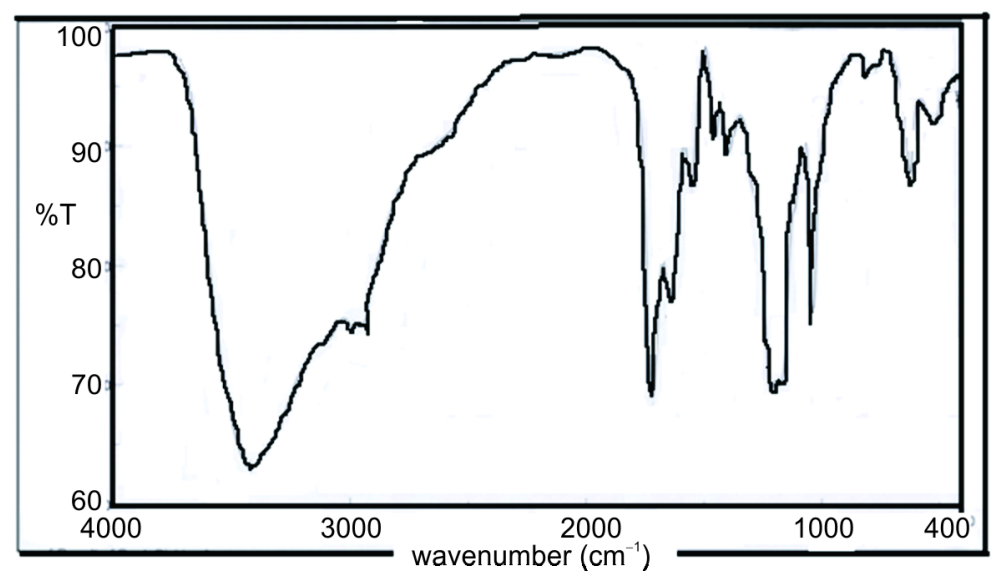

Figure 3. FTIR spectrum of linear AMPS/AA (30/70) copolymers.

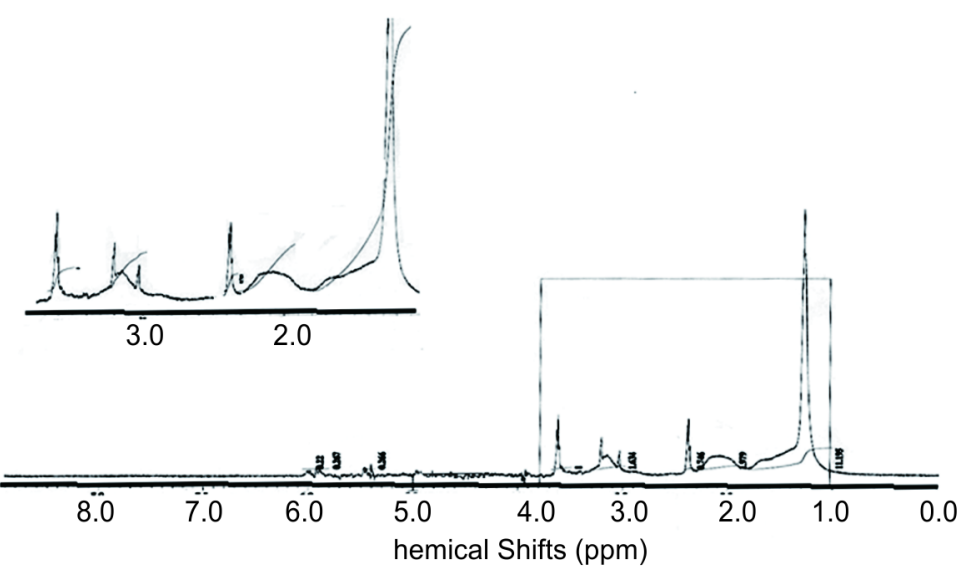

Figure 4. ${ }^{1} \mathrm{HNMR}$ spectrum of AMPS/AA copolymer.

\subsection{Effect of Different Binders on Coated Paper Properties}

During this work, two approaches were taken in preparation of coating binders: copolymerization of various ratio of acrylic acid with AMPS and copolymerization of acrylic acid with maleic anhydride.

The copolymers of AMPS with acrylic (20:80, 30:70, 50:50, 60:40, and 90:10) did not show any adhesion when applied in pigment suspension. The copolymers of acrylic with maleic anhydride showed adhesion of pigment together and adhesion to the base paper at different degree depending on the maleic: acrylic ratio. Another trial of mixing of the prepared copolymers of AMPS: acrylic acid and maleic anhydride: acrylic acid were carried out only the mixture of (AMPS: acrylic acid: 30\%:70\%) with (maleic anhydride: acrylic acid 50\%:50\%) which showed a degree of adhesion to the pigment particles and to the base paper. The applicable copolymers are illustrated in Table 1.

The effect of various binders on coated paper roughness at top side before and after calendering is represented in Table 2. The results show that coated paper containing MA:AA 50:50 binder has the lowest roughness compared to the other prepared binders and commercial binder, where paper roughness slightly increased upon using MA:AA (90:10), MA:AA (10:90), MA:AA (70:30) and MA:AA (30:70) binders. The blend between MA:AA and AMPS binders shows the highest roughness for coated paper. After calendering the roughness highly decreased in all samples as shown in Table 2. Coated paper having MA:AA (50:50) binder is still smoother than others samples even the commercial one (Acronal), where the blend binder still has more roughness.

A possible explanation is that, in uncalendered paper, the clay platelets are oriented rather randomly. On applying calendering under pressure, the clay platelets are pressed into the coating, squeezing out the binder polymer, which flows sideways filling adjacent depressions. As a result the micro roughness of the coated surface is reduced [21]. 

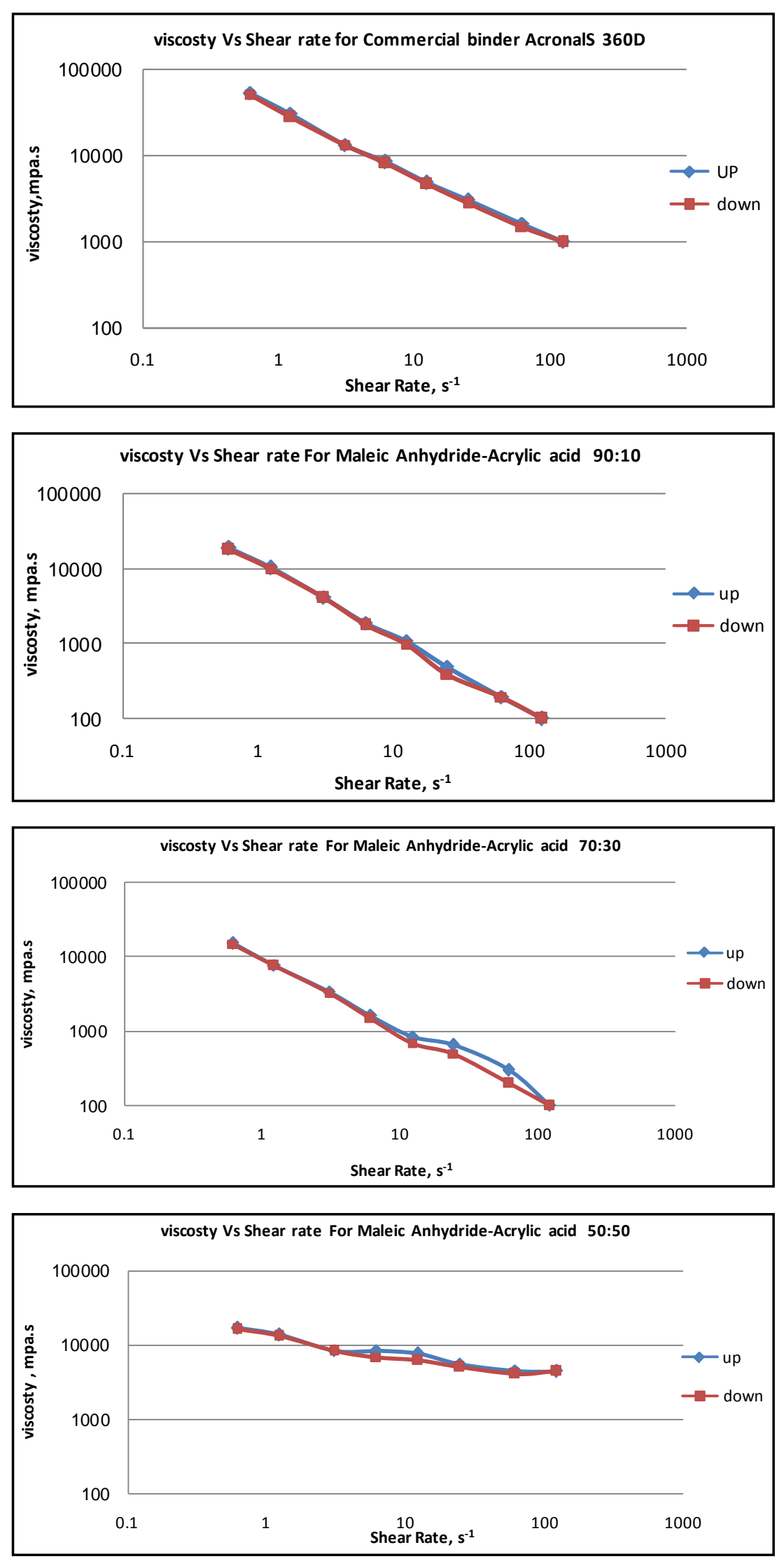

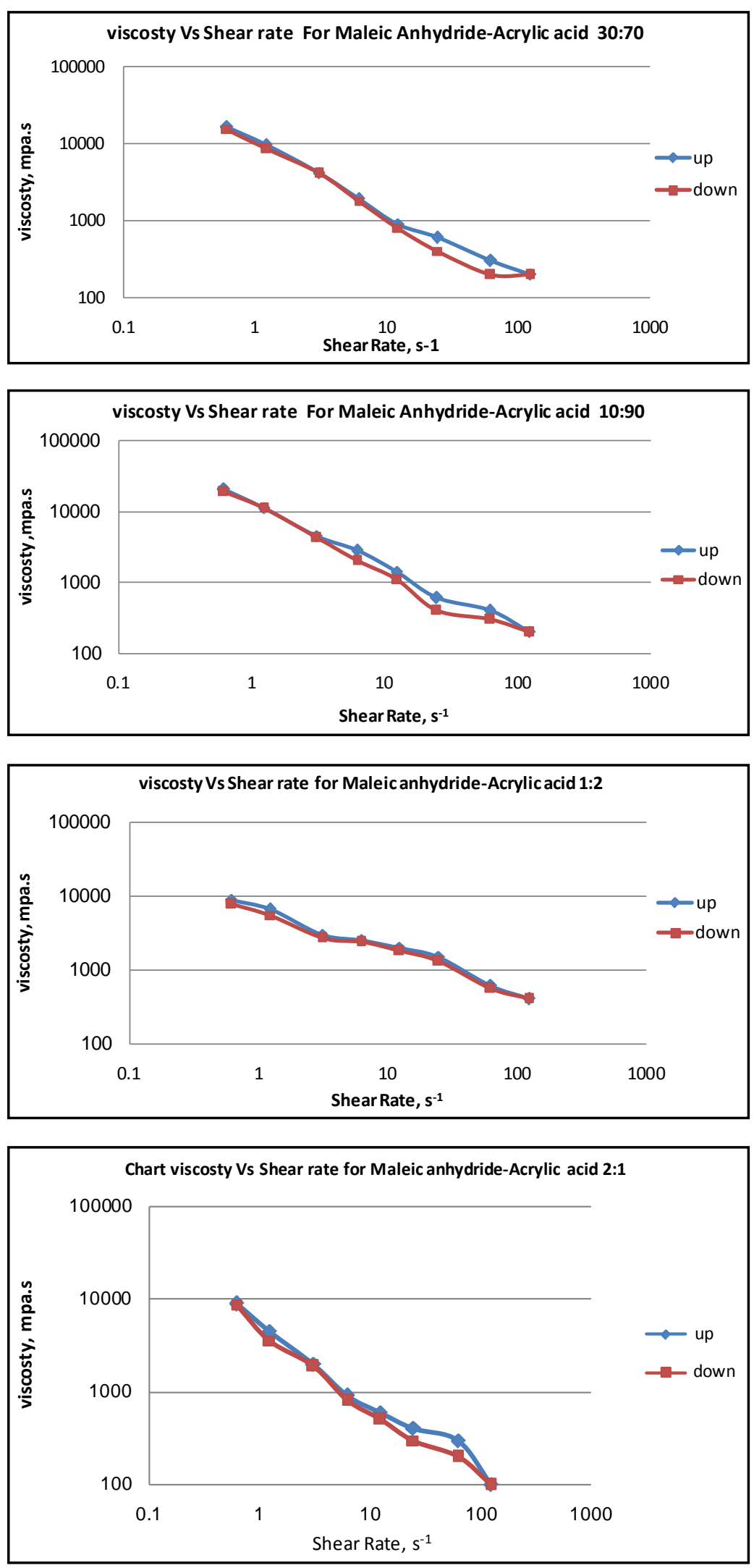

Figure 5. Viscosity vs. shear rate of Maleic Anhydride-Acrylic Acid. 


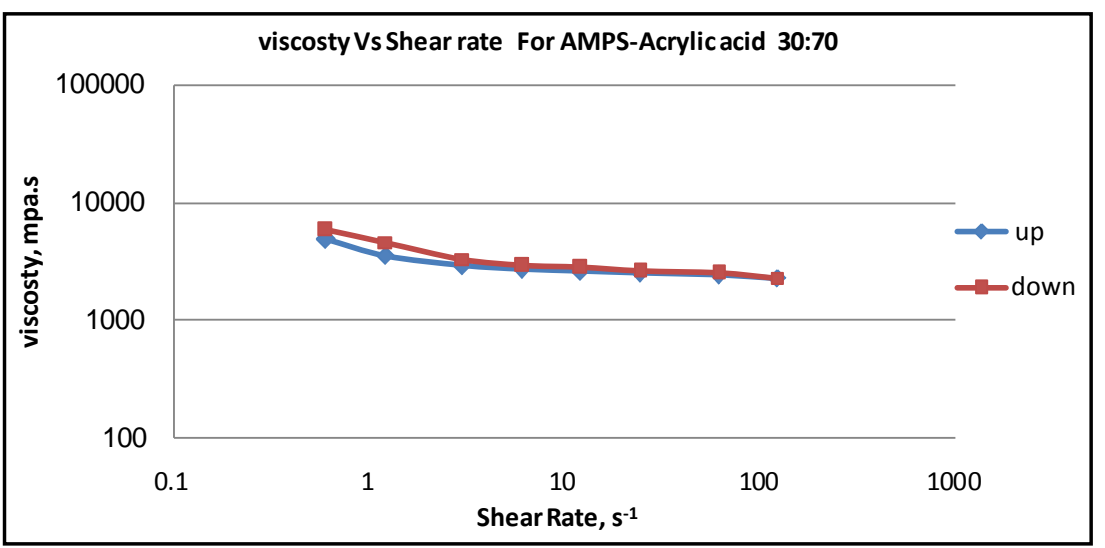

Figure 6. Viscosity vs. shear rate of AMPS-Acrylic Acid.

Table 2. Effect of various binders on coated paper properties before and after calendaring.

\begin{tabular}{|c|c|c|c|c|c|c|c|}
\hline \multirow[b]{2}{*}{ Binder designation } & \multicolumn{2}{|c|}{ Roughness ml/min } & \multirow{2}{*}{$\begin{array}{l}\text { Brightness } \\
\%\end{array}$} & \multicolumn{2}{|c|}{ Gloss $^{\circ}$} & \multirow{2}{*}{$\begin{array}{c}\text { Tensile } \\
\text { strength } \\
\mathrm{N} / \mathrm{m}\end{array}$} & \multirow{2}{*}{$\begin{array}{c}\text { Burst } \\
\text { strength } \\
\text { Kpa }\end{array}$} \\
\hline & $\begin{array}{l}\text { Before } \\
\text { calendaring }\end{array}$ & $\begin{array}{c}\text { After } \\
\text { calendaring }\end{array}$ & & $\begin{array}{l}\text { Before } \\
\text { calendaring }\end{array}$ & $\begin{array}{c}\text { After } \\
\text { calendaring }\end{array}$ & & \\
\hline Acronal S 360D & 128 & 69 & 81.2 & 12.5 & 14.8 & 5.04 & 228.47 \\
\hline MA:AA 90\%:10\% & 128 & 87 & 81.3 & 7.3 & 9.2 & 4.8 & 217.38 \\
\hline MA:AA 70\%:30\% & 147 & 76 & 81.1 & 6.7 & 8.6 & 4.7 & 218.56 \\
\hline MA:AA 50\%:50\% & 114 & 68 & 81.3 & 8.2 & 12.5 & 5.2 & 231.4 \\
\hline MA:AA 30\%:70\% & 153 & 94 & 81.5 & 5.5 & 6.8 & 4.9 & 228.55 \\
\hline MA:AA 10\%:90\% & 133 & 85 & 81.8 & 4.9 & 6.1 & 4.68 & 231.16 \\
\hline MA:AA 2:1 & 120 & 83 & 81.1 & 9.4 & 10.1 & 4.8 & 223.16 \\
\hline MA:AA 1:2 & 174 & 71 & 81.6 & 7.3 & 11.5 & 5.16 & 239.51 \\
\hline $\begin{array}{c}\text { Blend } \\
\text { (MA/AA 50:50 + AMPS/AA 30:70) }\end{array}$ & 191 & 117 & 82.2 & 4.5 & 5.9 & 4.88 & 209.43 \\
\hline
\end{tabular}

The effect of various binders on coated paper brightness is shown in Table 2. The results show that the prepared binders gave coated paper brightness higher than the commercial one, where MA:AA + AMPS:AA blend shows the highest brightness, as blending the two binders led to lowering the carboxyl content in the binder which changes its chemical structure. Decreasing the maleic anhydride ratio in the prepared polymers led to a decrease in carboxyl content in the final polymer, which consequently increased the coated paper brightness, This is confirmed from the results of the two samples MA:AA (1:2) and MA:AA (2:1). There is a significant negative correlation between the carboxyl content and the degree of brightness [22].

The effect of various binders on coated paper gloss at top side before and after calendaring is also shown in Table 2. Gloss is differently affected by the presence of different binders. The greatest gloss value was obtained with coated paper containing the commercial binder (Acronal S 360D). MA:AA 50:50 binder has the highest gloss value of the prepared binders where AMPS/AA blend binder has the lowest gloss. The improvement of some samples gloss is correlated with the surface roughness. It has been shown that gloss is predominantly governed by the surface texture of the paper [21]. Reducing the roughness of the coated surface leads to an increase in gloss. This is consistent with the equation that relates specular gloss to surface roughness.

$$
\ln \text { gloss } \propto-(4 \pi \sigma \cos \theta / \lambda)
$$

where:

$\alpha$ is a surface roughness parameter defined as the standards deviation of the surface roughness from the mean plane of the surface;

$\theta$ is the angle of incident light;

$\lambda$ is the wavelength of the incident light. 
Also the effect of various binders on coated paper tensile strength of machine direction (MD) and burst strength is shown in Table 2. The results indicated that MA:AA 50:50 and MA:AA 1:2 binders show a high tensile strength more the commercial binder and higher than the other binders. The high tensile and burst strength of these binders may be due to these types of binder show higher network structure than other binders as shown in Figure 5 and Figure 6 which also enhance the adhesion between the coat layer and the base paper.

\subsection{Effect of Different Binders on Print Quality of Coated Paper}

Table 3 shows the effect of different binders on print density of coated paper. Coated paper containing MA:AA 50:50 binder has the highest print density like that the coated paper containing the commercial binder Acronal S 360D but that containing MA:AA 90\%:10\% and the blend have lower print density values than them. The coated paper containing MA:AA 70:30, MA:AA 70:30 and MA:AA 10:90 have the lowest print density. Coated papers having both Acronal S 360D and MA:AA 50:50 showed the lowest roughness of all prepared coated papers having the others binders. This process of smoothing the paper surface improves (increases) the potential area of contact between the ink film and the paper surface. This effectively increases the amount of ink transferred to the paper, and consequently the concentration of pigment on the surface [23] [24].

The effect of different binders on print gloss of coated paper is illustrated in Table 3. The print gloss of coated paper containing Acronal S 360D has the highest print gloss this may be due to increase the amount of ink transferred which leads to increasing the print gloss. MA:AA 50:50 has the higher print gloss than the other prepared binders where the blend MA:AA + AMPS has the lower print gloss than the others. These results are in accordance with the results of measuring coated paper gloss and roughness. Low print gloss is an indication of a rough print surface, and this often means that the print density is also low, resulting in a poor image and poor colour reproduction [25].

\subsection{Photomacrography}

The macrographs of printed coated papers have different binders at different magnification $(4 \times, 10 \times)$ are shown in Figures 7 to 18.

Figure 7 is photomacrograph of offset prints on paper coated with clay coating mixture of commercial binder. It is shown a uniform printed surface with good distribution of ink without any picking up of coated surface. This can explain the higher print density of this coated paper samples and the high mechanical properties. This type of binder shows good adhesion properties to clay pigments together and with the base paper.

Comparing with the prepared binders, it is shown that MA/AA 50:50, MA/AA 2:1, and the blend MA/AA + AMPS/AA binders gave high good adhesion properties and homogeneous distribution of ink without any picking as shown in Figure 11, Figure 12, Figure 16, Figure 17 and Figure 18 respectively. Where upon using MA/AA 90:10 and MA/AA 30:70, (Figure 8 and Figure 13) it is shown that some the coat layers are removed and the greatest effect is shown for MA/AA 70:30, 10:90 binders (Figure 9, Figure 10 and Figure 14).

Table 3. Effect of various binders on printed coated paper properties.

\begin{tabular}{|c|c|c|}
\hline Binder designations & Print Gloss ${ }^{\circ}$ & Print Density \% \\
\hline Acronal S 360D & 19.8 & 0.68 \\
\hline MA:AA 90:10 & 10 & 0.52 \\
\hline MA:AA 70:30 & 7 & 0.36 \\
\hline MA:AA 50:50 & 10.6 & 0.68 \\
\hline MA:AA 30:70 & 6.8 & 0.35 \\
\hline MA:AA 10:90 & 6.7 & 0.34 \\
\hline MA:AA 2:1 & 11.8 & 0.45 \\
\hline MA:AA 1:2 & 9.8 & 0.53 \\
\hline Blend (MA/AA 50:50 + AMPS/AA 30:70) & 6.1 & 0.59 \\
\hline
\end{tabular}




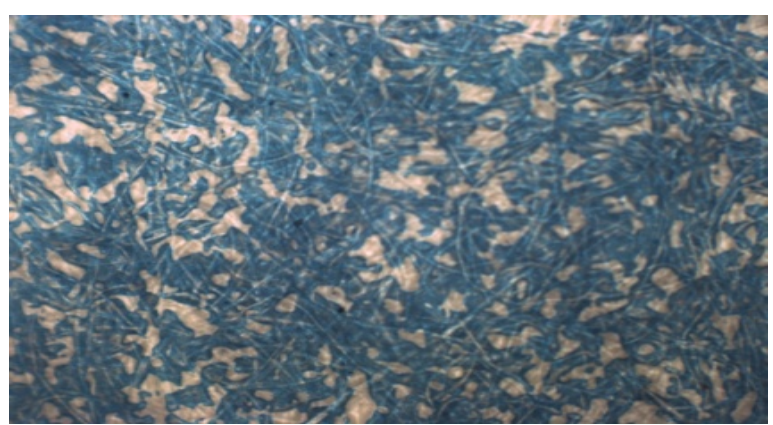

Figure 7. Photomacrograph of offset prints on paper coated with clay coating mixture containing commercial binder. At Magnification $\approx 4 \times$.

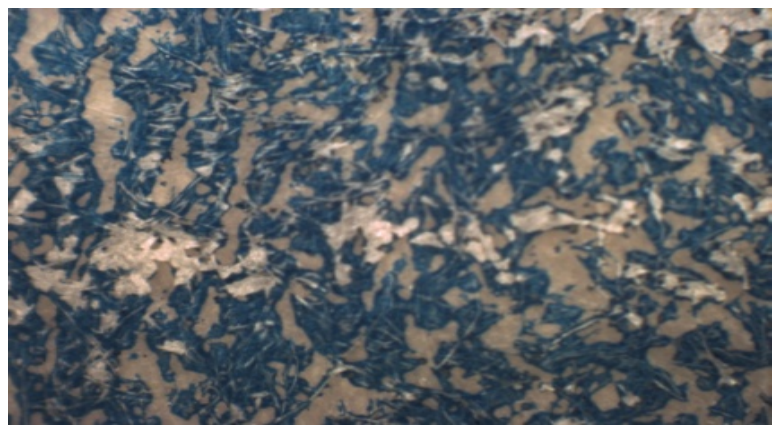

Figure 8. Photomacrograph of offset prints on paper coated with clay coating mixture containing MA/AA 90:10 binder. At Magnification $\approx 4 \times$.

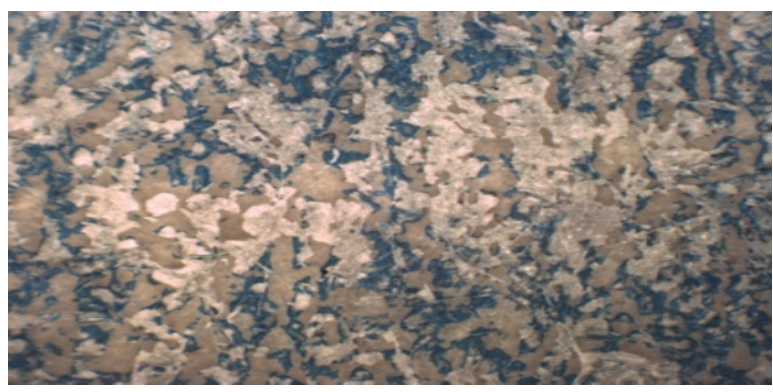

Figure 9. Photomacrograph of offset prints on paper coated with clay coating mixture containing MA/AA 70:30 binder. At Magnification $\approx 4 \times$.

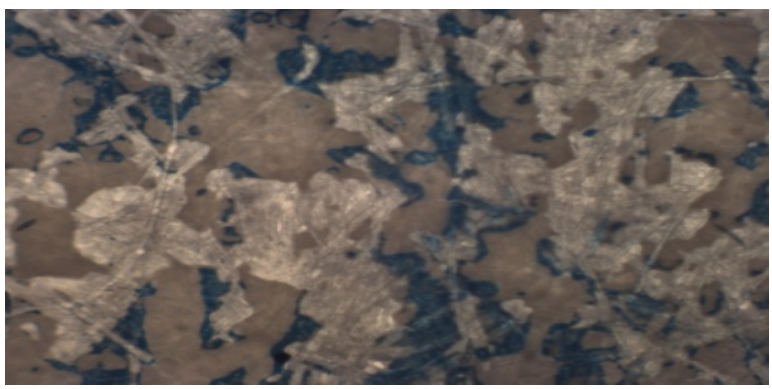

Figure 10. Photomacrograph of offset prints on paper coated with clay coating mixture containing MA/AA 70:30 binder At Magnification $\approx 10 \times$. 


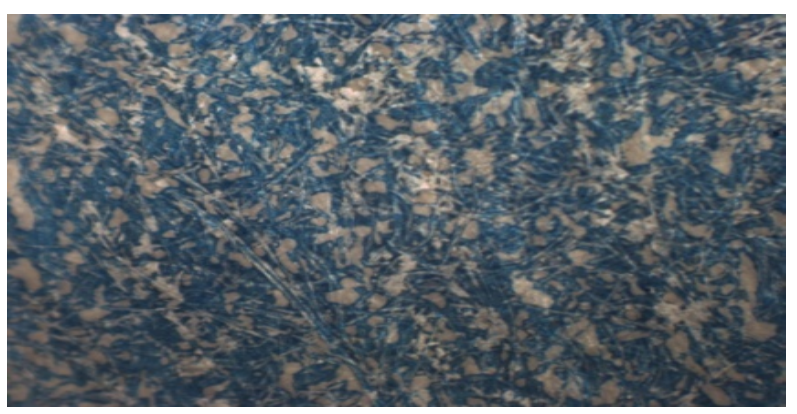

Figure 11. Photomacrograph of offset prints on paper coated with clay coating mixture containing MA/AA 50:50 binder. At Magnification $\approx 4 \times$.

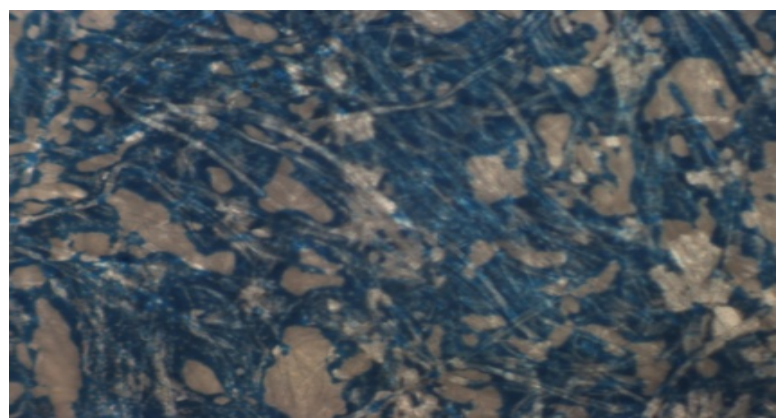

Figure 12. Photomacrograph of offset prints on paper coated with clay coating mixture containing MA/AA 50:50 binder. At Magnification $\approx 10 \times$.

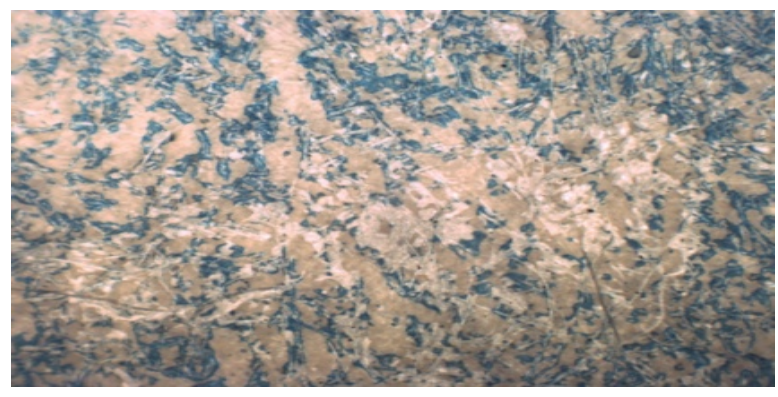

Figure 13. Photomacrograph of offset prints on paper coated with clay coating mixture containing MA/AA 30:70 binder. At Magnification $\approx 4 \times$.

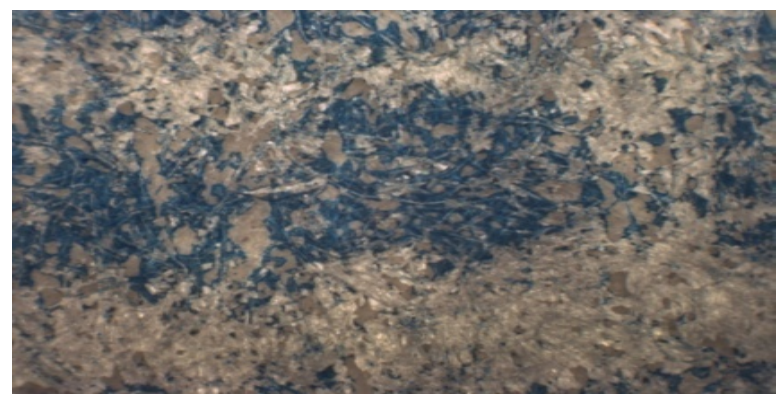

Figure 14. Photomacrograph of offset prints on paper coated with clay coating mixture containing MA/AA 10:90 binder At Magnification $\approx 4 \times$. 


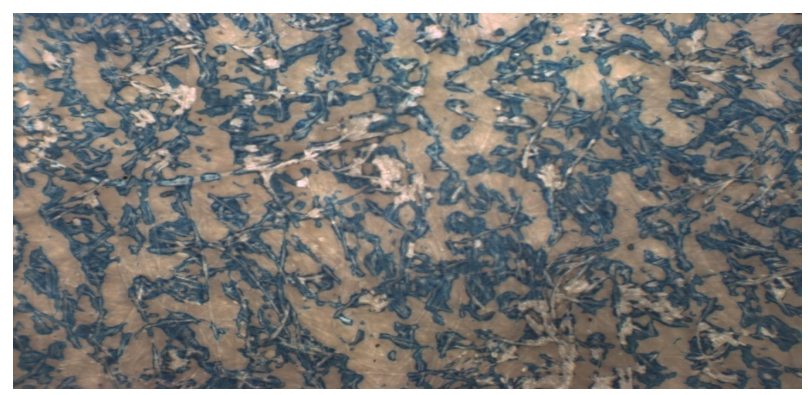

Figure 15. Photomacrograph of offset prints on paper coated with clay coating mixture containing MA/AA 1:2 binder. At Magnification $\approx 4 \times$.

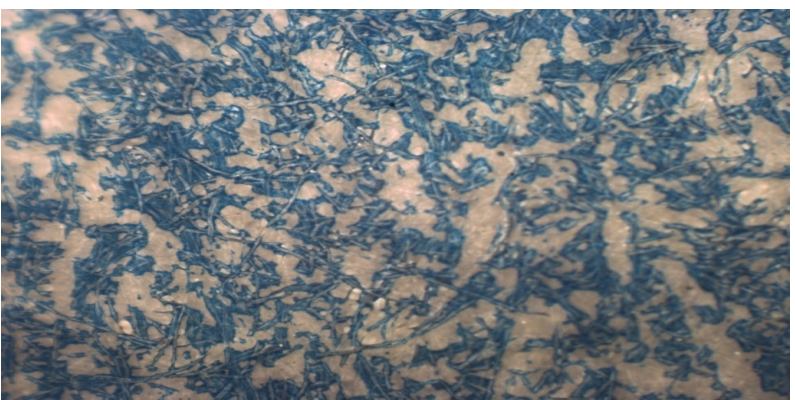

Figure 16. Photomacrograph of offset prints on paper coated with clay coating mixture containing MA/AA 2:1 binder. At Magnification $\approx 4 \times$.

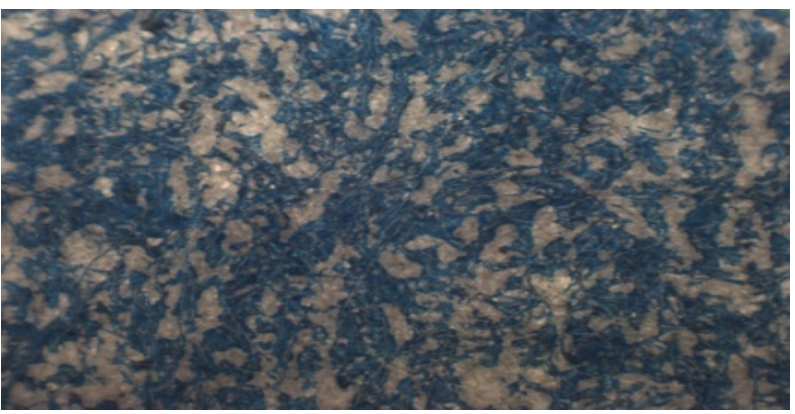

Figure 17. Photomacrograph of offset prints on paper coated with clay coating mixture containing (MA/AA + AMPS/AA) blend binder. At Magnification $\approx 4 \times$.

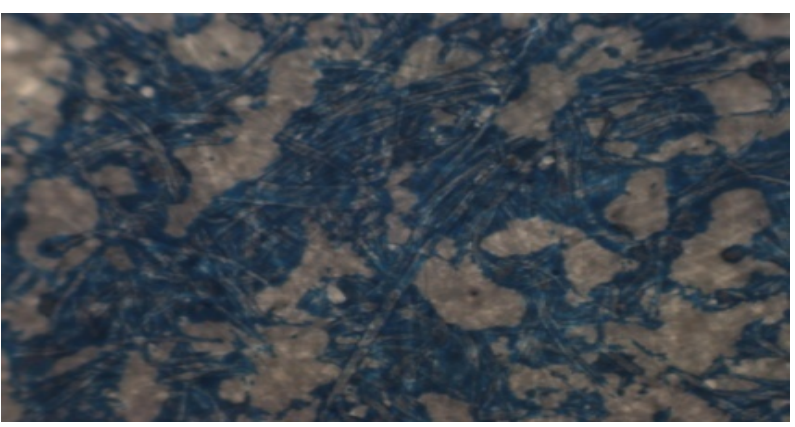

Figure 18. Photomacrograph of offset prints on paper coated with clay coating mixture containing (MA/AA+AMPS/AA) blend binder. At Magnification $\approx 10 \times$. 


\section{Conclusions}

The following conclusions can be withdrawn from the previous results in the following points:

- The results revealed that the polymerization between water soluble maleic anhydride acrylic acid with different maleic anhydride ratios and the blend have a good effect on paper coating which improve the optical properties such as brightness and gloss.

- MA/AA 50:50 binder shows higher mechanical properties than the other prepared binders, in addition it has lower roughness and high print density.

- As the maleic anhydrides ratio increased the pick resistance of the coated paper decreased.

- MA/AA 50:50, MA/AA 2:1 and the blend binders have more suitable coating film properties and have the most pick resistance as the commercial binder Acronal S 360D.

\section{References}

[1] Morsy, F.A. and El-Sherbiny, S. (2004) Mechanical Properties of Coated Paper: Influence of Coating Properties and Pigment Blends. Journal of Materials Science, 39, 7327-7332. http://dx.doi.org/10.1023/B:JMSC.0000048747.93113.6d

[2] Holik, H. (2006) Handbook of Paper and Board, Chapter 7. WILEY-VCH Verlag GmbH \& Co. KGaA, Weinheim.

[3] Hanciogullari, H. (2000) Pigment Coating and Surface Sizing of Paper. In: Gullichsen, J. and Paulapuro, H., Eds., Papermaking Science and Technology, Vol. 11, Fapet Oy, Helsinki.

[4] Casey, J.P. (1983) Pulp and Paper Chemistry and Chemical Technology. 3rd Edition, Hagemeyer, R.W., John Wiley and Sons, New York.

[5] Gron, J. (2000) Pigment Coating and Surface Sizing of Paper. In: Gullichsen, J. and Paulapuro, H., Eds., Papermaking Science and Technology, Vol. 11, Fapet Oy, Helsinki.

[6] Smook, G.A. (1997) Handbook for Pulp \& Paper Technologists. 2nd Edition, Angus Wilde Publications Inc., Bellingham.

[7] Willenbacher, N. and Hanciogullari, H. (1997) TAPPI, Advanced Coating Fundamentals Symposium Notes. TAPPI Press, Atlanta.

[8] Larsson, M., Engström, G., Vidal, D. and Zou, X. (2007) Impact of Calendering on Coating Structures. Nordic Pulp and Paper Research Journal, 22, 267-274. http://dx.doi.org/10.3183/NPPRJ-2007-22-02-p267-274

[9] Bohlin, E. (2011) Optics of Coated Paperboard-Aspects of Surface Treatment on Porous Structures. Karlstad University, Karlstad.

[10] Yoshida, E., Tago, S. and Imamura, K. (1984) Binders Compositions for Paper Coating Materials. US Patent No. 4431769.

[11] Mclaughlin, J., moorestowm, N. and Toy, W. (1957) Methods of Making Coated Paper Products and the Products Obtained. US Patent No. 2790736.

[12] Robert, W. and Hagemeyer, I. (1997) Pigments for Paper. Tappi Press, Technology Park, Atlant.

[13] Wesslau, H., Duerkheim, B. and Spoor, H. (1968) Binders for Paper Coating Compositions. US Patent No. 3365410.

[14] Hanford, E. (1945) Copolymers of Maleic Anhydride. US Patent No. 2378629.

[15] Wang, K., Huang, P., Xia, C., Gao, D. and Yan, D. (2002) Fluorescent Polymer Made from Chemical Modification of Poly (Styrene-Co-Maleic Anhydride). Reactive and Functional Polymers, 52, 143-148. http://dx.doi.org/10.1016/S1381-5148(02)00088-3

[16] Gaylord, N.G. (1975) Polymer Reviews-Poly Maleic Anhydride. Journal of Macromolecular Science, 13, $235-261$. http://dx.doi.org/10.1080/15321797508080011

[17] Heseding, C. and Schneider, C. (1976) Radiation-Induced Copolymerization of Maleic Anhydride and Phenanthrene. European Polymer Journal, 13, 387-390. http://dx.doi.org/10.1016/0014-3057(77)90101-X

[18] Zhou, Z., Xu, W., Fan, J., Ren, F. and Xu, C. (2008) Synthesis and Characterization of Carboxyl Group-Containing Acrylic Resin for Powder Coatings. Progress in Organic Coatings, 62, 179-182. http://dx.doi.org/10.1016/j.porgcoat.2007.10.007

[19] Atta, A.M., El-Hamouly, S.H., AlSabagh, A.M. and Gabr, M.M. (2007) Crosslinked Poly (Octadecene-Alt-Maleic Anhydride) Copolymers as Crude Oil Sorbers. Journal of Applied Polymer Science, 105, 2113-2120. http://dx.doi.org/10.1002/app.26326

[20] Atta, A.M. and Friedrich, K. (2005) Characterization of Strong Polyelectrolyte Hydrogels Based on Poly(Vinyl Alco- 
hol). Polymer International, 54, 448-455. http://dx.doi.org/10.1002/pi.1718

[21] Caner, E., Farnood, R. and Yan, N. (2008) Relationship between Gloss and Surface Texture of Coated Papers. Tappi Journal, 7, 19-26.

[22] Nada, A.M.A. and Ibrahem, A.A. (1986) Grafting of Acrylamide onto Partially Acetylated and Carboxy Methylated Cellulose. Acta Polymerica, 37, 320-322. http://dx.doi.org/10.1002/actp.1986.010370516

[23] Preston, J.S., Elton, N.J., Legrix, A., Nutbeem, C. and Husband, J.C. (2002) The Role of Pore Density in the Setting of Offset Printing Ink on Coated Paper. Tappi Journal, 1, 3-5.

[24] Preston, J., Hiorns, A., Parsons, D.J. and Heard, P. (2008) Design of Coating Structure for Flexographic Printing. Paper Technology, 49, 27-36.

[25] Oittinen, P. and Saarelma (2000) Printing. In: Gullichsen, J. and Paulapuro, H., Eds., Papermaking Science and Technology, Vol. 13, Fapet Oy, Helsinki. 